\title{
Notes on the vocalizations of Grey-barred Wren (Campylorhynchus megalopterus)
}

Peter Boesman

In the following we briefly analyze and compare voice of the two races of Grey-barred Wren (Campylorhynchus megalopterus). We also try to quantify the extent of any vocal differences using the criteria proposed by Tobias et al. (2010), as a support for taxonomic review. We have made use of sound recordings available on-line from Xeno Canto (XC).

From the available recordings, it would seem that the main two vocalizations are harsh chattering series of notes, and somewhat longer harsh notes typically given rather well spaced.

nelsoni

Chattering series:
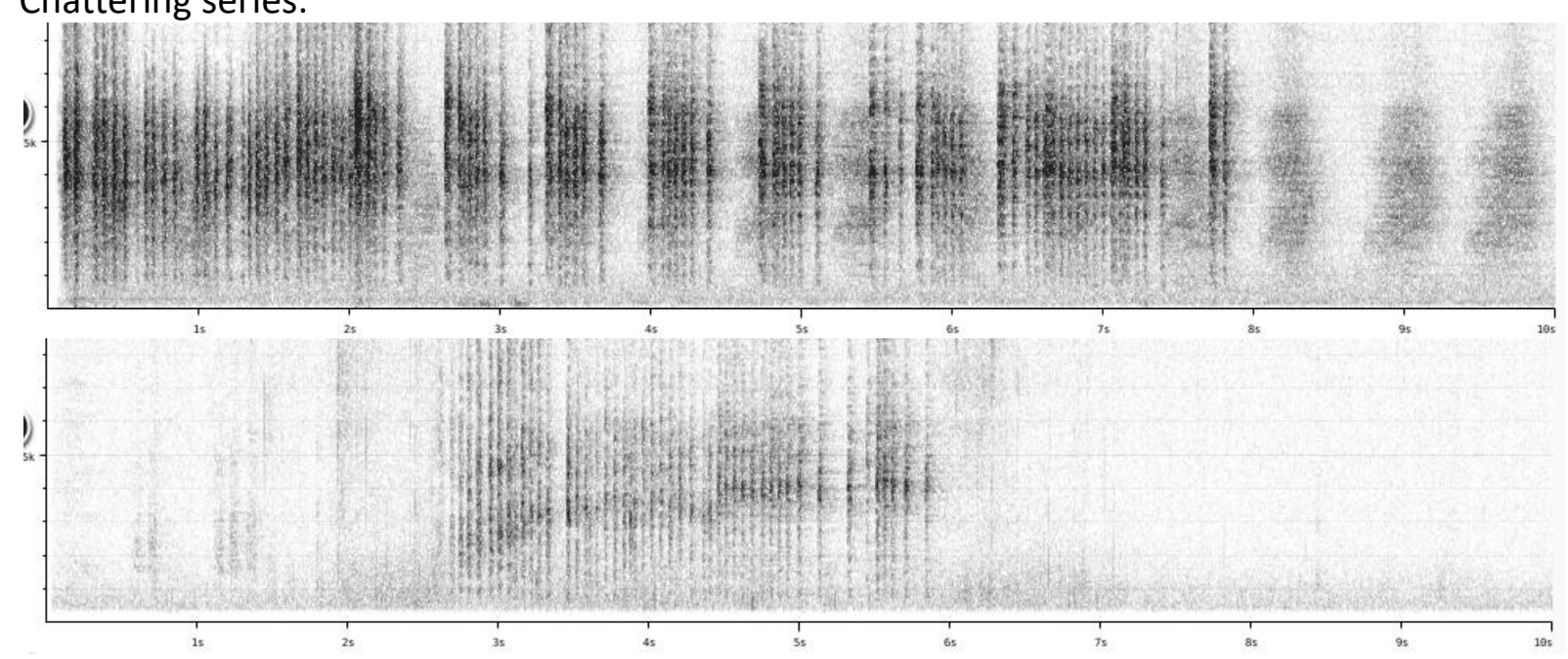

Spaced longer call notes:

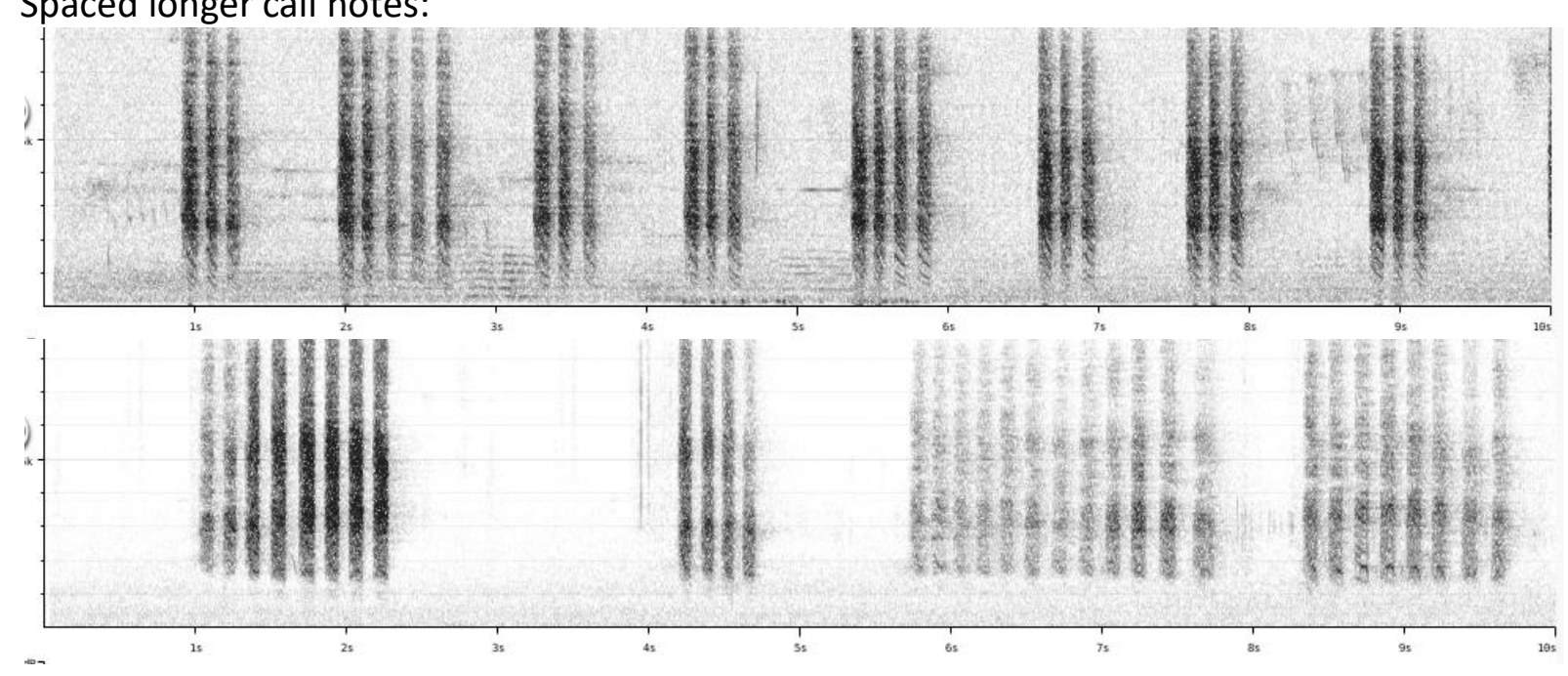



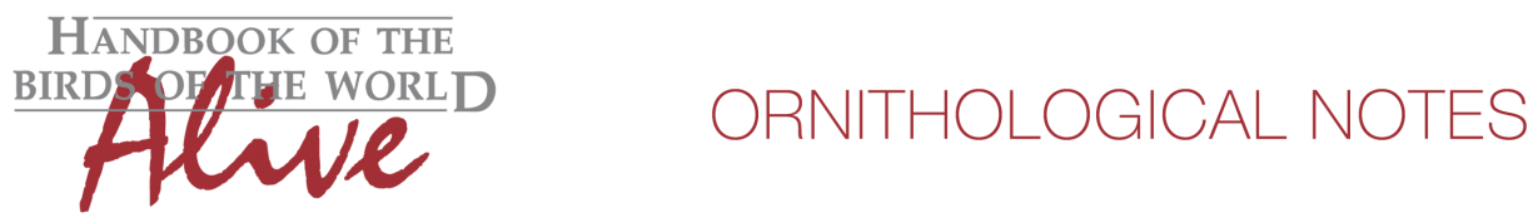

megalopterus

Chattering series:
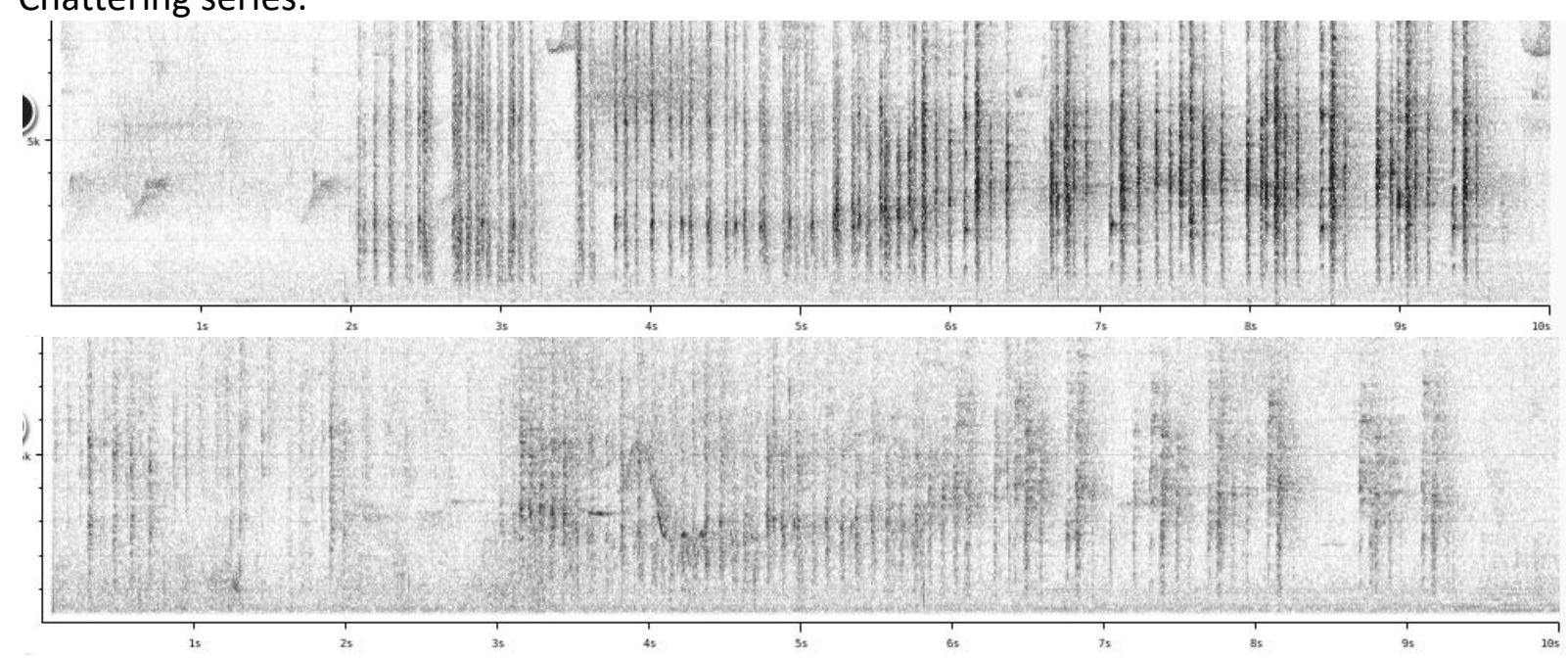

We could not locate any recording of race megalopterus illustrating the 'spaced long call notes', all available recordings being of the rapid chattering of shorter notes $(n=12)$. Obviously, absence of recordings does not mean absence of vocalization, but it may be an indication this voice type is not used or much less so than in the southern race.

This note was finalized on 15th April 2016, using sound recordings available on-line at that moment. We would like to thank in particular the sound recordists who placed their recordings for this species on XC: Peter Boesman, Allen Chartier, Manuel Grosselet, DJon King, an Lane, Juan Carlos Pérez, Andrew Spencer and Pat Wade.

\section{References}

Tobias, J.A., Seddon, N., Spottiswoode, C.N., Pilgrim, J.D., Fishpool, L.D.C. \& Collar, N.J. (2010). Quantitative criteria for species delimitation. Ibis 152(4): 724-746.

\section{Recommended citation}

Boesman, P. (2016). Notes on the vocalizations of Grey-barred Wren (Campylorhynchus megalopterus). HBW Alive Ornithological Note 287. In: Handbook of the Birds of the World Alive. Lynx Edicions, Barcelona. (retrieved from http://www.hbw.com/node/1251729 on 12 October 2016). 